\title{
Evaluation on Undergraduate Entrepreneurs Quality Based on Questionnaire Survey
}

\author{
CAI Lihui \\ School of Economics \\ Chongqing Technology and Business University \\ Chongqing Municipality, China \\ 164604252@qq.com
}

\author{
RAO Guangming \\ Economics and Management Experimental Teaching Center \\ Chongqing Technology and Business University \\ Chongqing Municipality, China \\ 2421149491@qq.com \\ Corresponding author
}

\begin{abstract}
Based on the questionnaire survey of undergraduate entrepreneurs, this paper establishes the entrepreneur quality synthetic index induding 12 indicators and empirically measures the potential undergraduate entrepreneurs' self-assessment of their internment quality and ability. The result shows that the psychological quality, ability quality and ideological and moral qualities of contemporary undergraduate entrepreneurs are badly in need of being promoted through using social practices, strengthening students' entrepreneurial ability, developing students' insights and innovative thinking and training the student to respond to rapidly changing market.
\end{abstract}

Keywords- Undergraduate Entrepreneurs Quality and Ability; Evaluation; improvement

Peter Drucker said that what qualities an entrepreneur has is the key to enterprise's success and survival. What are the factors affecting the improvement of undergraduate entrepreneurs' quality and ability in the process of college students' entrepreneurship ?

\section{CONNOT ATION OF UNDERGRADUATE ENTREPRENEURS QUALITY}

Entrepreneurs are the cores of a pioneering enterprise [1]. It refer to innovative people who are active in the creation and enterprise growth stage and organize enterprise production factors, promote economic reforms, provide the new value for the market [2]. Entrepreneurs' quality is that the entrepreneurs equipping with their psychological, social culture show stable level of organizational elements, and quality of body and mind under the action of the surrounding environment and education activities ${ }^{[3]}$. As an entrepreneur, entrepreneurship means they must prepare fully to take risks, to accept the challenge. And it is a test the entrepreneurs of psychological quality, ability quality, ideological quality. The psychological quality includes willpower, risk awareness, achievement motivation; internal control tendency main ly includes the knowledge ability literacy and social cooperation ability, strain transformation ability, self awareness, etc., Ideological quality includes the honest code of honor, social responsibility, etc. [3]. College students' entrepreneurial quality covers the psychological quality, ability, thought, etc. As a special social and emerging business groups which had not experienced so much, if they want to be successful businessman and they must have a better psychological quality than other entrepreneurs, and dare to take responsibilities when encountered difficulties and setbacks, and full of self-confidence. At the same time, entrepreneur should also realize that establishing and running a business is not an easy thing, just having good psychological quality is not enough, and also need to have strong ability of comprehensive quality. So you can determine your own entrepreneurial orientation and management mode according to each domain, so as to lay solid foundation for the successful entrepreneurship. As the new generation of higher education, college student entrepreneurs should stick to social moral standards, good ideological and moral cultivation. A Pursuiting economic interest is not the only goal, but to enhance their social responsibility to get leading role. In the current innovative social background, the entrepreneur is one of the extremely scarce resources. How is the level of the current undergraduate entrepreneurs?

\section{CONSTRUCTION OF THE ENTREPRENEURS QUALITY EVALUATION INDEX SYSTEM}

Based on the analysis of the college entrepreneurs' quality and intention, we have learned that the college entrepreneurs' quality consists of three dimensions [4], mainly includes the psychological quality; ability quality and moral qualities. In order to know the specific situation of the entrepreneurs' quality, the author organized a questionnaire for the students in entrepreneurship experimental class, which mainly focuses on the College entrepreneurs' quality, which involves the psychological quality, ability quality, moral qualities and 12 secondary indicators [5]. The survey data defines the score set as $E=$ \{strongly against, against, neutral, agree, strongly agree $\}$, corresponding to the score as $E=\{1,2,3,4,5\}$.The total score is 60 points, we selected 67 college entrepreneurs as the sample, and give out 67 questionnaires, actually we collect 47 questionnaires, the effective recovery rate is $70.01 \%$. The students in entrepreneurship experimental class come from different grades. Some of them have intention to have selfemployment but lack of start-up project, some have projects but have not put it into practice, the others, of course, have reached the entrepreneurial success. The questionnaires are covering a wide range, as well as have certain representativeness. Based on the data analysis, the index system of a reasonable evaluation is set up ${ }^{[1]}$ ( see table 1 ) with 
the specific steps listed as follow: firstly we set a target evaluate set named $Y$, the secondly target set is $Y=\left\{X_{1}\right.$, $\left.X_{2}, X_{3}\right\}$, each secondly target $X_{i}$ is influenced by each indicator $X_{i j}[6]$. Based on the interview data, we set the index set as $X_{i j}$ $(i=1,2,3, j=1 \ldots 6)$.

TABLE I. THE ENTREPRENEUR'S QUALITY EVALUATION INDEX SYSTEM

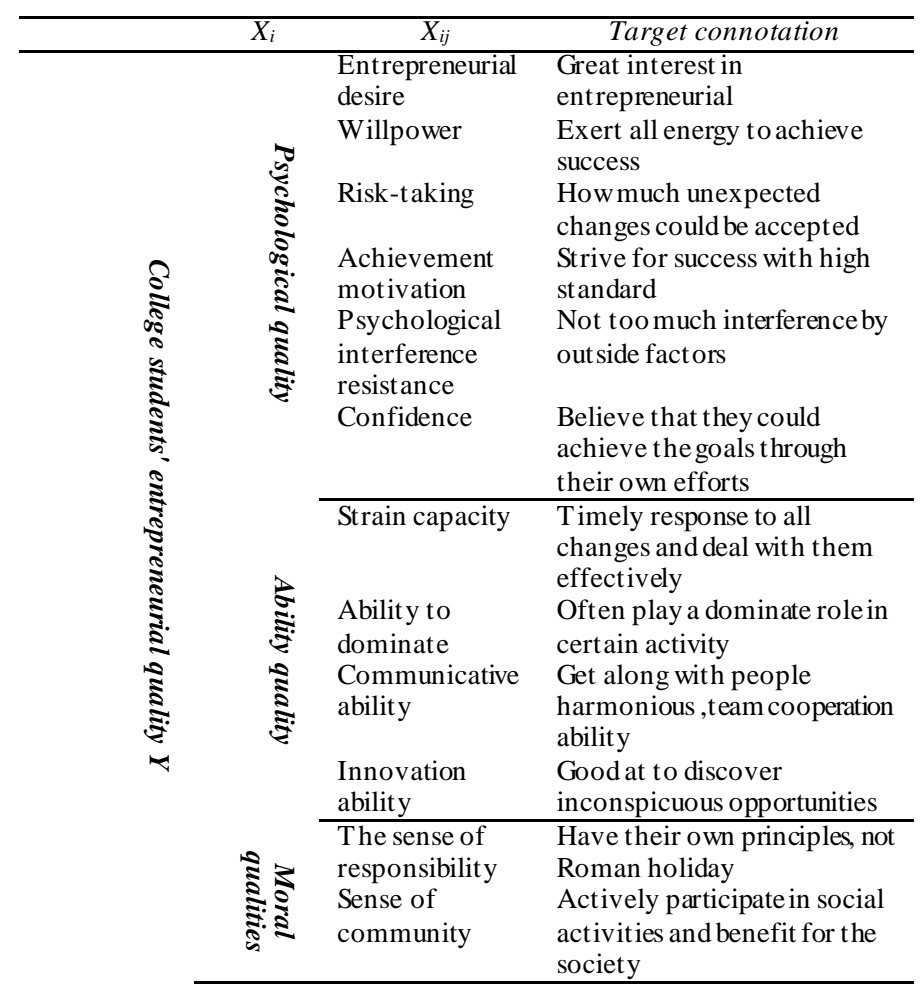

\section{EMPIRICAL ANALYSIS}

In this section, the first and second target set would be transformed into assessment item based on the college entrepreneurs' quality evaluation index system, then collect questionnaire data for statistical processing.

First of all, average calculated every index. According to the average measure what qualities is relative deficient or relative higher in college entrepreneur; Then we make a principal component analysis of the secondary index system to reduce the dimension of the data set, and remove less comprehensive variables to reflect the original data set information.

\section{A. Undergraduate entrepreneurs qualityoverall situation analysis}

Based on the entrepreneur quality evaluation index system, combining with the effective questionnaire, we make a statistic analys is on the overall situation for the college entrepreneurs as showed in table II. We can see that the mean $X_{1}$ (psychological quality) , $X_{2}$ (ability quality) , $X_{3}$ (moral qualities ) index were $3.80,3.08,4.16$, which shows that students' entrepreneurs ability quality is relatively lack relative to the psychologicalquality and moral quality.
TABLE II.

QUALITY OVERALL SITUATION ANALYSIS

\begin{tabular}{cccc}
\hline Indicator & Average & Indicator & Average \\
\hline$Y$ & 3.62 & $X 2$ & 3.08 \\
$X 1$ & 3.80 & $X 21$ & 3.66 \\
$X 11$ & 4.13 & $X 22$ & 3.23 \\
$X 12$ & 4.38 & $X 23$ & 3.53 \\
$X 13$ & 3.77 & $X 24$ & 1.89 \\
$X 14$ & 3.96 & $X 3$ & 4.16 \\
$X 15$ & 2.91 & $X 31$ & 4.11 \\
$X 16$ & 3.64 & $X 32$ & 4.21 \\
\hline
\end{tabular}

The total score of the sample is 5 points, and the average point of college entrepreneurs' moral quality is 4.16 , this shows that the new generation who received higher education have much stronger social responsibility on the basis of the $X_{1}$

(psychological quality) , $X_{2}$ (ability quality) , $X_{3}$ (moral qualities ) value analysis, and shows that the entrepreneurs' comprehensive quality, mental ability and moral quality is closely linked. Comparing with the total score 5 points, $Y$ (college students' entrepreneurial quality) averages 3.62. This medium point shows that college entrepreneurs' comprehensive ability needs further improve. In psychological quality $X_{1}$

(psychological quality), the value of $X_{12}$ (willpower) is far ahead other indicators, the corresponding value is 4.38 . This shows that in today's superior material environment, college students' entrepreneurs still inherited the hard struggle of the Chinese nation's fine tradition. They would spend all the energy until success. However, the average value of $X_{12}$ (willpower), $X_{15}$ (Psychological interference resistance) is 2.91 points, which is relatively low. The corresponding content in the questionnaire is that the Psychological anti-jamming capability is weak. Students are vulnerable to outside influence. On the side of schooling, teachers should strengthen the psychological education and improve students' psychological quality, with the intention to lay the foundation for cultivating students to be high quality entrepreneurs. In $X_{2}$ ( ability quality) , the value of $X_{24}$ (The innovation ability) is 1.89 ; the corresponding content is innovation ability. This means that innovation ability is serious lack in college student's group.This is also closely lined with the living environment and education. In the context of an innovative society, as the country's new generation successor, contemporary college students have the responsibility as well as obligation to cultivate their innovation ability, contributing to build an innovative country.

\section{B. Principal component model analysis}

Principal component analysis (PCA) is a technology of simplified, analysis data sets. It simplified a lot of correlation index (indicators $\mathrm{j}$, for example) to a new and comprehensive index which is not related to each other, then use the new composite indicator to replace a number of indicators. In math it is usually through linear integrated comprehensive a new index [7]. The first step is choosing the first comprehensive index of F1 variance $\operatorname{VAR}\left(F_{1}\right)$ to express. The higher value $\operatorname{VAR}\left(F_{1}\right)$ get, the more information contained in F1.Therefore, $F_{1}$ should be the largest index in all linear 
combination and used as first principal component. If the first principal component is not enough to represent the original $j$ index information, it would be needed to consider choosing the second linear combination $F_{2}$. In order to reflect the orig in information effectively, the existing information in F1 should not appear in $F_{2}$, which means $\operatorname{COV}(F 1, F 2)=0$ [7]. Now we call $F_{2}$ as the second principal components, then we could construct the third, fourth... the first $\mathrm{j}$ is a principal component.

Mathematical model of principal component analysis:

$$
\begin{aligned}
& F_{1}=a_{11} X_{1}+a_{21} X_{2}+\cdots+a_{p 1} X_{j} \\
& F_{2}=a_{12} X_{1}+a_{22} X_{2}+\cdots+a_{p 2} X_{j} \\
& \cdots \cdots \\
& F_{n}=a_{1 m} X_{1}+a_{2 m} X_{2}+\cdots+a_{n m} X_{j}
\end{aligned}
$$

$a_{1 i} a_{2 i}, \ldots \ldots, a_{n i}(i=1, \ldots \ldots, m)$ define as the Feature vectors of $X$, s Covariance matrix' s Characteristic polynomial, In practical application, the existing indicators dimension is different. Before making a data processing, the influence of dimensional should be eliminated, and then standardized the original data. $X_{1}, X_{2}, X_{j}$ is the original variable values after standardized treatment [8].

\section{Data validity check}

Before making the comprehensive analysis, we need to analysis the selected indicators and data for inspection to see whether they could be applied to the global principal components analysis. This article chose the Bartlett spherical test method and KMO sampling adequacy measurement method.

KMO sampling and test method of spherical appropriateness measurement method, coupled with the questionnaire survey data, we get the statistics in the following table:

TABLE III.

KMO AND BARTLETT'S TEST

\begin{tabular}{lr|r}
\hline $\begin{array}{l}\text { Sampling enough degrees of Kaiser - Meyer - } \\
\text { Olkin measurements. }\end{array}$ & 0.658 \\
The approximate chi-square & 109.590 \\
Bartlett sphericity test method & df \\
& Significant & 66 \\
\end{tabular}

KMO is one of the important indicators for measuring variables correlation, KMO value between o and 1.The higher KMO value represent the stronger correlation between variables ${ }^{[8]}$. On contrary, the lower KMO value represent the weaker correlation between variables. In table 3, KMO value is 0.658 (Great than 0.5), this represents the strong correlation between variables. The common factors are existed in different indicators. Bartlett sphere in the case of df is 66 degrees, approximate chi-square value is 109.590 , significance is 0.001 . Reject units related hypothesis, the data is suitable for the global principal components analysis.

\section{Principal component analysis}

We carry on the principal component analysis through the actual recycling 47 questionnaires data. The initial characteristic value of the global principal component and the variance contribution rate (variance contribution rate, the cumulative variance contribution rate) shown in Table 4.

Table 4 shows that the cumulative variance contribution rate of the first eight principal components reached $86.477 \%$, which preserves the original sample index information, can be analyzed on behalf of the original sample data.

\begin{tabular}{cccc} 
TABLE IV. & \multicolumn{3}{c}{$\begin{array}{c}\text { EIGENVALUES AND CUMULATIVE VARIANCE } \\
\text { CONTRIBUTION RATE }\end{array}$} \\
\hline $\begin{array}{c}\text { Principal } \\
\text { Component }\end{array}$ & $\begin{array}{c}\text { Initial } \\
\text { eigenvalues }\end{array}$ & $\begin{array}{c}\text { Variance } \\
\text { contribution rate } \\
(\%)\end{array}$ & $\begin{array}{c}\text { Cumulative } \\
\text { variance } \\
\text { contribution rate } \\
(\%)\end{array}$ \\
\hline 1 & 2.913 & 24.279 & 24.279 \\
2 & 1.481 & 12.340 & 36.619 \\
3 & 1.288 & 10.731 & 47.350 \\
4 & 1.186 & 9.885 & 57.235 \\
5 & 1.026 & 8.552 & 65.786 \\
6 & 0.981 & 8.177 & 73.963 \\
7 & 0.781 & 6.505 & 80.468 \\
8 & 0.721 & 6.009 & 86.477 \\
\hline
\end{tabular}

So the text extracted eight main components were analyzed separately named F1 to F8, the factors affect college students entrepreneurs quality principal components can be summarized as eight. As is shown in table 5, the load matrix by the maximu $\mathrm{m}$ variance spinning processing, get the corresponding eigenvectors, and then construct the principal component matrix according to the feature vector.

\begin{tabular}{c|cccccccc}
\multicolumn{1}{c}{ TABLE V. } & \multicolumn{7}{c}{ Principal Component } \\
\cline { 2 - 9 } Variable & $\boldsymbol{F}_{1}$ & $\boldsymbol{F}_{2}$ & $\boldsymbol{F}_{3}$ & $\boldsymbol{F}_{4}$ & $\boldsymbol{F}_{5}$ & $\boldsymbol{F}_{6}$ & $\boldsymbol{F}_{7}$ & $\boldsymbol{F}_{8}$ \\
\hline$X_{11}$ & 0.652 & -0.377 & -0.081 & 0.366 & 0.203 & 0.009 & -0.183 & 0.023 \\
$X_{12}$ & -0.075 & -0.109 & 0.774 & 0.158 & -0.344 & 0.129 & 0.113 & 0.359 \\
$X_{13}$ & 0.440 & -0.388 & 0.065 & 0.117 & 0.159 & 0.689 & -0.158 & 0.127 \\
$X_{14}$ & 0.335 & 0.279 & 0.142 & 0.517 & -0.439 & 0.119 & 0.134 & -0.473 \\
$X_{15}$ & 0.637 & 0.008 & 0.280 & 0.297 & 0.218 & -0.375 & -0.165 & -0.173 \\
$X_{16}$ & -0.065 & 0.405 & 0.362 & 0.046 & 0.754 & 0.098 & 0.176 & -0.071 \\
$X_{21}$ & 0.613 & -0.149 & 0.075 & -0.101 & 0.024 & -0.196 & 0.636 & 0.199 \\
$X_{22}$ & 0.828 & 0.124 & -0.095 & -0.319 & -0.059 & -0.053 & 0.088 & -0.035 \\
$X_{23}$ & 0.720 & 0.008 & -0.049 & -0.308 & -0.141 & -0.171 & -0.280 & 0.154 \\
$X_{24}$ & 0.408 & 0.505 & -0.058 & -0.359 & -0.074 & 0.490 & 0.077 & -0.127 \\
$X_{31}$ & 0.130 & 0.775 & 0.097 & 0.173 & -0.049 & -0.092 & -0.290 & 0.379 \\
$X_{32}$ & 0.063 & 0.203 & -0.647 & 0.538 & 0.021 & 0.081 & 0.229 & 0.305 \\
\hline
\end{tabular}


As can be seen from table 5, the larger load of $F_{1}$ on $X_{11}$, $X_{15}, X_{21}, X_{23}, X_{24}$ in the first PCA show larger correlation with these indicators, and mainly reflect the quality of the entrepreneurial desire level, psychological resistance to interference, resilience, ability to lead, communication capabilities .The larger load of $F_{2}$ on $X_{24}, X_{31}$ in the second PCA show larger correlation with these indicators, and mainly reflect the quality level of innovative and responsibility of entrepreneur. The larger load of $F_{3}$ on $X_{12}$ in the third PCA show larger corre lation with these indicators, and illustrate the quality level of entrepreneurial willpower. The larger load of $F_{4}$ on $X_{14}, X_{32}$ in the fourth PCA show larger correlation with these indicators and more fully illustrate the quality level of achievement motivation and social responsibility of the entrepreneur. The larger load of $F_{5}$ on $X_{16}$ in the firth PCA shows greater correlation with confidence. The larger load of $\mathrm{F}_{6}$ on $X_{13}, X_{24}$ in the sixth PCA show strong correlation with risk and innovation, and reflect the quality aspect of risktaking of entrepreneur and innovation ability level. The larger load of $F_{7}$ on $X_{21}$ in the seventh PCA show strong correlation between the two, and fully reflects the resilience of entrepreneurs in the level of quality. The larger load of $F_{8}$ on $X_{12}, X_{31}$ in the eighth PCA mainly reflect the quality level of responsibility and willpower of entrepreneurial quality.

\section{E. Building entrepreneurial quality composite index}

Introducing the coefficient, the main characteristic values and standardized data of each index on the table into each of the main component analysis of expression, and respectably calculate the score of eight main ingredients. Then we regard contribution rate of eight main ingredients as weights and structure entrepreneurial quality composite index F. Following formula:

$$
F=\sum_{i=1}^{n} w_{i} F_{i}
$$

Where: $W_{i}$ representing of the weight of $\mathrm{i}$-th principal component, $F i$ is the i-th principal component, $F$ as the score of evaluation for main ingredients of entrepreneurial quality. Final results of calculation as follows:

$F=0.0996 X_{11}+0.0938 X_{12}+0.1245 X_{13}+0.0988 X_{14}+0.1248 X$ $15+0.1733 X_{16}+0.1350 X_{21}+0.1007 X_{22}+0.0404 X_{23}+0.1180 X_{24}+$ $0.1338 X_{31}+0.0741 X_{32}$

By the same process, separately through principal component analysis can build the score of entrepreneurial quality of psychological quality, competency and ideological quality, scores of principal component of 47 concrete samples as shown in appendix table 1.

\section{COMPREHENSIVE ANALYSIS}

\section{A. Importance analysis of the index}

We get the Linear equation about $F$ and 12 secondary indexes by analyzing the main ingredients. The coefficient stands for the importance of index for the quality of entrepreneur, as showing in figure 1.
Based on the questionnaire, Figure 1 shows those students who attended this survey marked themselves on those related questions. From it, students assessed them the highest on X16

(confidence), which shows that they think the mselves have a strong confidence when involving in entrepreneurship. And those students who assessed themselves a relatively high score on those factors such as $X_{21}$ (strain capacity), $X_{31}$ (the sense of responsibility), $X_{15}$ (psychological interference resistance), $X_{13}$ (risk-taking), $X_{24}$ (innovation ability). They gave themselves a relatively low score on $X_{22}$ (ability to dominate), $X_{11}$ (entrepreneurial desire), $X_{14}$ (achievement motivation), $X_{12}$ (willpower), $X_{32}$ (sense of community). Significantly , they all marked a lowest score on $X_{23}$ (Communicative ability).

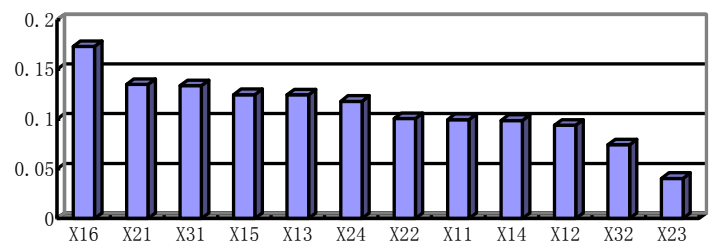

Figure 1. Ranking of index factors

This fully demonstrate that, college students who have never gone to the society have not formed a high level of understanding the entrepreneurial qualities, and they think that self-confidence is their best factor that affects entrepreneurial quality. And the importance of strain capacity, sense of responsibility, psychological anti-interference ability, risktaking, innovation ability come second, relative to the previous factors, the assessment of leading ability, entrepreneurial desires, achievement motivation, determination, sense of social and communication skills is relatively weak. This on the other hand reveals that the college students need to be provided more opportunities to integrate into the society, to deep their understanding of society, to develop their skills

\section{B. Undergraduate entrepreneur quality evaluation}

In order to better analyze entrepreneurs quality evaluation result, established the standard of college students' entrepreneurial quality score hierarchies and qualification, according to the grading standard based on psychological quality $(P Q)$, ability quality $(A Q)$, ideological quality $(I Q)$, and comprehensive quality ( $C Q$ ), 47 samples of college students' entrepreneurial quality score statistical analysis, as shown in table 6 .

TABLE VI. GRADING STANDARDS

\begin{tabular}{lllll}
\hline Grade & outstanding & good & qualified & Unqualified \\
\hline Standard & & $0 \leqslant X$ & $-0.5 \leqslant X$ & \\
acuity & $X \geqslant 0.5$ & $<0.5$ & $<0$ & $X<-0.5$ \\
\hline$P Q$ & $14.9 \%$ & $40.4 \%$ & $31.9 \%$ & $12.8 \%$ \\
$A Q$ & $23.4 \%$ & $14.9 \%$ & $38.3 \%$ & $23.4 \%$ \\
$M Q$ & $44.7 \%$ & $0.0 \%$ & $34.0 \%$ & $21.3 \%$ \\
$C Q$ & $8.5 \%$ & $40.4 \%$ & $38.3 \%$ & $12.8 \%$ \\
\hline
\end{tabular}

As can be seen from table 6 , in all 47 valid samples, only four entrepreneurs achieve excellent comprehensive quality, 
accounted for at least $8.5 \%$; Good category most, accounting for $40.4 \%$ of the total sample; Qualified second, accounted for $38.3 \%$; And the unqualified are 6 , accounted for $12.8 \%$. This is also consistent with reality. For students to make business, usually have a certain entrepreneurial qualities and belong ings to the active and outstanding group in college students. Nevertheless, what really has good quality is a few, because of business risk big success probability smaller. And for entrepreneurs entrepreneurship quality is unqualified, can through the practice of entrepreneurship to recognize their deficiencies, life is also very useful for correct planning.

Further dimensions analys is from the psychological quality, ability quality and ideological quality, is conducive to further grasp the basic situation of the current college students' entrepreneurial quality. Looking from the psychological quality and comprehensive quality, excellent samples accounted for only 14.9\%; Good category accounted for most, 40.4\%; Qualified category number is slightly lower than good category, accounting for more than $31.9 \%$; Unqualified number covers $12.8 \%$. Relative to the psychological quality, the ability of entrepreneur quality excellence rate is higher, toll to $23.4 \%$; A good category is low, 14.9\%; Qualified number relative to other categories is the most, 38.3\%; But ability quality of unqualified ratio is also the highest, at $23.4 \%$, reflecting ability literacy is low, quite a number of entrepreneurs should be aroused the concern of the school, society and actively provided all kinds of students who are committed to the entrepreneurial practice to make practice to improve their capabilities needed.

From the perspective of the distribution of entrepreneurs to ideological quality, excellent ranks high proportion, accounted for $44.7 \%$, the qualified ranks second, accounted for $34.0 \%$; Unqualified $21.3 \%$, while good category accounted for $0.0 \%$. This reflects, on the one hand, the college students ideological quality overall is higher, covering nearly half, with strong social sense of responsibility; on the other hand, entrepreneurs polarization or serious ideological quality need to continue to strengthen ideological and moral construction in the entrepreneurial practice. Through above analysis, it is easy to find that comparing to the college students entrepreneurs ability quality and ideological quality excellence rate, psychological quality excellence rate is relatively lower, entrepreneurs in life should be attention to the cultivation of their psychological quality, schools should also strengthen to cultivate students psychological quality, with attention to the student ability quality improvements, so as to improve college students' entrepreneurial success probability and create more employment opportunities.

\section{CONCLUSION}

The paper set up an index system to evaluate undergraduate entrepreneurs' quality. Combined with statistical and measurement methods, it makes empirical analys is for quality of current undergraduates venture based on questionnaire survey. The results show that the overall quality of undergraduate entrepreneurs is currently optimistic. Especially with outstanding ideological quality, college student entrepreneurs have strong sense of social responsibility, while the psychological quality, ability quality and ideological quality all need to be improved on. The level of quality not only affects the entrepreneurial result, but also has a significant impact on the entrepreneurial environment and other entrepreneurs' attitude.

Governments, schools and society should participate in activities to develop undergraduate entrepreneurs' quality, including cultivation of psychological quality to improve college student entrepreneurs' risk-taking ability and spirit of endure hardship and ideological quality, enhancing their sense of responsibility and community.

\section{LIMIT ATIONS AND NEXT STEPS}

Through the writing of this paper, I learned many useful things, and also accumulated a lot of experience. However, as lack of capacity, coupled with the limited time and energy, this paper has some shortcomings. Firstly, because of the limitations of many aspects, the investigation object is only in a certain area, not involving a wide range. Secondly, the sample is not large enough. This affects the reliability of data analysis. This can be done better in future research with more experiences and experiments in undergraduate entrepreneurship.

\section{ACKNOWLEDGMENTS}

This paper is supported by the 2015 Bayu overseas program of introducing talents of Chongqing Technology and Business University and the research program on the teaching reform of colleges and Universities of Chongqing municipality supported by Chongqing Education Commission of China under grant 132036.

\section{REFERENCES}

[1] Zhu Yongyue, HuBei. Research entrepreneurs' quality evaluation based on wavelet neural network [J] .Science \& Technology Progress and Policy, 2011, 05: 115-119.

[2] DEAKINS D, FR EEL M. Entrepreneneurship and small firms [M] .CA: McGraw Hill, 2009.

[3] Zhang Dongmei, College students' entrepreneurial basic quality analysis - A Case of Hebei North University [J]. Journal of Hebei North University, 2012,04: 113-116.

[4] Zhu Yongyue, HuBei. Entrepreneur Quality of industrial clusters based on evolution perspective [J]. Scientific Management Research, 2010, 03: 106-108.

[5] Jiang Jun, Chen Demian, Xie Shengqiang. Entrepreneurs quality and complete independence Index of [J]. Finance and Trade Research, 2008,04: 147-148.

[6] Chen Hait ao, Zhao Haigang, Jing Xudi. The independence of the quality of entrepreneurs and completeness index collection research [J]. Information Science, 2006, 07:974-979.

[7] Mao Cuiyun, Mei Qiang. Entrepreneurs' quality model and the comprehensive evaluation method [J]. Statistics and Decision, 2009, 24: 59-61.

[8] Zhang Wenlin. Principal component analysis in the application of satisfaction with the weight [J]. Market ing Research, 2006 practices: 18 to 22 . 


\section{APPENDIX}

Table1 scores of entrepreneurs quality

\begin{tabular}{|c|c|c|c|c|}
\hline & PQ & $\mathrm{AQ}$ & MQ & CQ \\
\hline 1 & 0.90 & 1.55 & 0.74 & 0.83 \\
\hline 2 & 0.62 & 1. 47 & 0.74 & 0.68 \\
\hline 3 & 0.62 & 1. 46 & 0.74 & 0.63 \\
\hline 4 & 0.57 & 0.9 & 0.74 & 0.52 \\
\hline 5 & 0.55 & 0.83 & 0.74 & 0.44 \\
\hline 6 & 0.52 & 0.83 & 0.74 & 0.44 \\
\hline 7 & 0.50 & 0.8 & 0.74 & 0.42 \\
\hline 8 & 0.49 & 0.75 & 0.74 & 0.41 \\
\hline 9 & 0.48 & 0.73 & 0.67 & 0.40 \\
\hline 10 & 0.43 & 0.62 & 0.67 & 0.38 \\
\hline 11 & 0.43 & 0.58 & 0.67 & 0.34 \\
\hline 12 & 0.42 & 0.48 & 0.67 & 0.32 \\
\hline 13 & 0.37 & 0.39 & 0.67 & 0.3 \\
\hline 14 & 0.37 & 0.17 & 0.67 & 0.25 \\
\hline 15 & 0.35 & 0.09 & 0.67 & 0.22 \\
\hline 16 & 0.35 & 0.08 & 0.67 & 0.17 \\
\hline 17 & 0.33 & 0.01 & 0.6 & 0.17 \\
\hline 18 & 0.23 & 0 & 0.6 & 0.13 \\
\hline 19 & 0.15 & -0.01 & 0.6 & 0.11 \\
\hline 20 & 0.14 & -0.02 & 0.6 & 0.1 \\
\hline 21 & 0.13 & -0.07 & 0.6 & 0.07 \\
\hline 22 & 0.08 & -0.08 & -0.12 & 0.06 \\
\hline 23 & 0.07 & -0.08 & -0.12 & 0.03 \\
\hline 24 & 0.03 & -0.08 & -0.12 & -0.04 \\
\hline 25 & 0.03 & -0.11 & -0.12 & -0.06 \\
\hline 26 & 0 & -0.11 & -0.12 & -0.07 \\
\hline 27 & -0.02 & -0.11 & -0.12 & -0.07 \\
\hline 28 & -0.09 & -0.14 & -0.19 & -0.07 \\
\hline 29 & -0.12 & -0.18 & -0.19 & -0.08 \\
\hline 30 & -0.19 & -0.19 & -0.19 & -0.09 \\
\hline 31 & -0.21 & -0.19 & -0.19 & -0.12 \\
\hline 32 & -0.21 & -0.2 & -0.19 & -0.15 \\
\hline 33 & -0.26 & -0.26 & -0.19 & -0.15 \\
\hline 34 & -0.3 & -0.28 & -0.19 & -0.2 \\
\hline 35 & -0.34 & -0.28 & -0.19 & -0.23 \\
\hline 36 & -0.34 & -0.46 & -0.26 & -0.25 \\
\hline 37 & -0.35 & -0.54 & -0.26 & -0.26 \\
\hline 38 & -0.35 & -0.55 & -0.98 & -0.3 \\
\hline 39 & -0.44 & -0.73 & -1.05 & -0.34 \\
\hline 40 & -0.49 & -0.74 & -1.05 & -0.36 \\
\hline 41 & -0.49 & -0.74 & -1.05 & -0.40 \\
\hline 42 & -0.58 & -0.75 & -1.05 & -0.51 \\
\hline 43 & -0.59 & -0.75 & -1.05 & -0.56 \\
\hline 44 & -0.74 & -0.94 & -1.12 & -0.57 \\
\hline 45 & -0.97 & -0.94 & -1.12 & -0.71 \\
\hline 46 & -1.02 & -1.00 & -1.12 & -0.74 \\
\hline 47 & -1.07 & -1.21 & -1.90 & -1.10 \\
\hline
\end{tabular}

